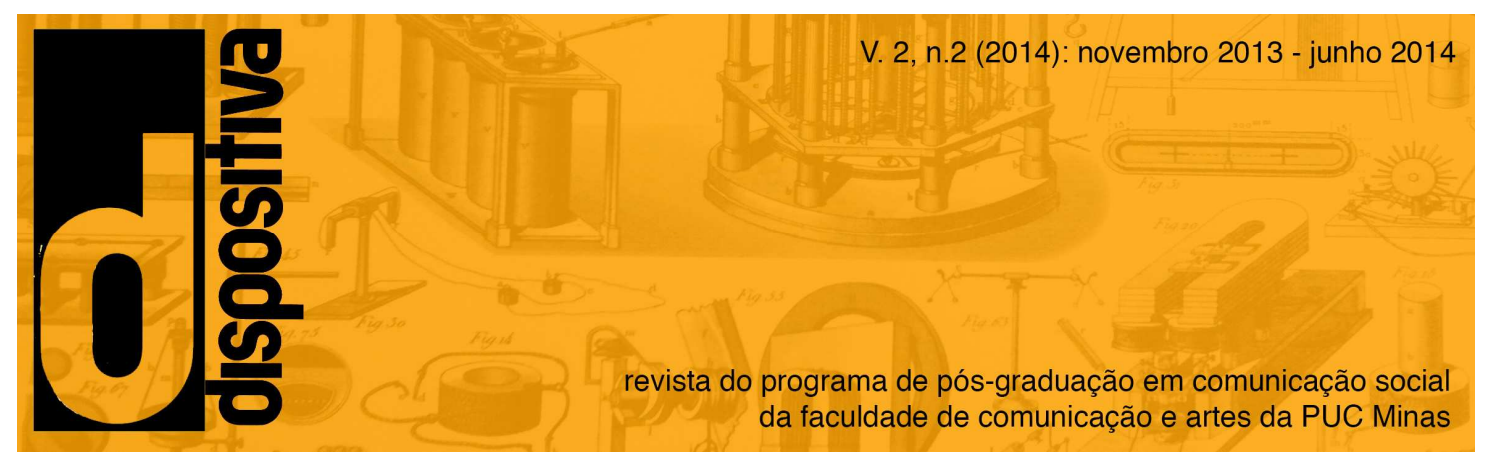

\title{
O DIÁLOGO, O ACONTECIMENTO E A CRIAÇÃO DE CENAS DE DISSENSO EM CONTEXTOS ORGANIZACIONAIS
}

\section{DIALOGUE, EVENT, AND THE CREATION OF SCENES OF DISSENSUS IN ORGANIZATIONAL CONTEXTS}

\author{
Ângela Cristina Salgueiro Marques ${ }^{1}$ \\ Rennan Lanna Martins Mafra²
}

\begin{abstract}
Resumo: Este artigo tem como objetivo compreender os mecanismos de operação do diálogo quando mobilizado nos contextos organizacionais. Inicialmente, buscaremos entender que o diálogo emerge nos contextos organizacionais a partir de um acontecimento que provoca a abertura de campos comunicativos sempre conflituosos. Em seguida, argumentamos que as interações provocadas pelo acontecimento dão origem a comunidades políticas que se manifestam em cenas de dissenso nas quais os integrantes dessas comunidades instituem um drama ancorado em gestos poéticos e argumentativos, voltados à sua própria constituição como interlocutores em torno de uma pretensa igualdade moral e política. Por fim, buscaremos entender como as comunidades políticas, que emergem das cenas de dissenso acontecimentais ao mesmo tempo em que as constróem, se valem do diálogo para dar visibilidade a (fazer aparecer) suas próprias diferenças em práticas articulatórias imprevisíveis, fragmentadas e conflituosas.
\end{abstract}

Palavras-chave: Diálogo. Acontecimento. Cenas de dissenso. Comunidade política. Pluralidade.

\footnotetext{
${ }^{1}$ Professora do Departamento de Comunicação Social e do Programa de Pós-Graduação em Comunicação Social da Universidade Federal de Minas Gerais (UFMG). Mestre e Doutora em Comunicação pela mesma instituição. E-mail: angelasalgueiro@gmail.com

2 Professor do Departamento de Economia Rural (Área Teorias da Comunicação e Desenvolvimento Socioeconômico) e do Programa de Pós-Graduação em Extensão Rural da Universidade Federal de Viçosa (UFV). Mestre e Doutor em Comunicação pela UFMG. E-mail: rennan.mafra@ufv.br.
} 


\begin{abstract}
The aim of this article is to understand the mechanisms by which dialogue operates when mobilized in the organizational contexts. First, we will search to understand that dialogue emerges in organizational contexts from an event that provokes the opening of communicative fields always marked by conflict. After that, we argue that the interactions derived from the event give origin to political communities that reveal themselves in scenes of dissensus in which their integrants institute a drama anchored in poetical and argumentative gestures, turned to its own constitution as interlocutors around an alleged moral and political equality. Finally, we will search to understand how political communities, which emerges of the événementiel scenes of dissensus at the same time they build them, make use of dialogue to give visibility (make appear) their own differences in unexpected, fragmented and conflictive practices.
\end{abstract}

Keywords: dialogue, event, scenes of dissensus, political community, plurality

\title{
1.Introdução
}

A reflexão em torno da constituição comunicativa das organizações nos apresenta, sob diversos aspectos, as condições sob as quais a comunicação cria as organizações (PUTNAM e NICOTERA, 2010). Autores como Fairhurst e Putnam (2004) apontam que não é a presença em si da comunicação e do diálogo que produzem uma organização, mas a ação coordenada, a colaboração, a legitimação de parceiros e a identificação por eles promovidas. Ao mesmo tempo, essa abordagem nos permite afirmar que o contexto organizacional, apesar de ser constituído pelas interações sociais, pelo uso comunicacional da linguagem e pelos discursos, não pode ser apreendido fora de tensões de poder e desigualdades que interferem no modo como o diálogo opera e funciona em tal contexto.

Fóruns de diálogo têm sido criados em contextos cívicos e organizacionais construindo regras e princípios para seu funcionamento inclusivo, paritário e reflexivo. Contudo, observamos que a emergência efetiva de vozes (e de interlocutores) ainda enfrenta problemas ligados às assimetrias de poder e à desvalorização de pontos de vista e/ou daqueles que os proferem. Muitos desenhos participativos e dialógicos em contextos organizacionais reduzem a concepção de "voz" (ou de tomar a palavra) a meramente ter algo a dizer, em vez de observar a construção social do que há para ser dito ou de quem deve dizê-lo e como (DEETZ e SIMPSON, 2003). 
Sob essa perspectiva, o objeto do diálogo é frequentemente associado ao conteúdo das falas, aos interesses em disputa e à solução de algum problema que se apresenta discursivamente diante de uma coletividade. Contudo, argumentamos que o objeto de um diálogo deve ser a própria possibilidade de sua ocorrência. É por isso que Rancière (2004) descreve o diálogo como a criação de uma cena polêmica na qual o conflito se estabelece acerca do entendimento da própria situação de fala, ou seja, do estatuto dos sujeitos falantes, de sua habilidade em apresentar ao outro o mundo no qual seus argumentos fazem sentido e da dinâmica dissensual que desestabiliza concepções pré-figuradas do que significa a interlocução e o processo de constituição dos interlocutores. Para esse autor, o diálogo produzido em cenas polêmicas é o evento fundante de comunidades políticas, nas quais um sentido de público é construído pela aparência e pelo engajamento comunicativo e agonístico.

Ao mesmo tempo, essas cenas se constituem e emergem por meio de acontecimentos específicos que, ao se desdobrarem, permitem que comunidades políticas se desenvolvam e deem origem a processos dialógicos marcados por uma lógica dissensual que requer uma observação mais atenta aos modos como os interlocutores se constituem enquanto tais, de maneira autônoma e paritária (MARQUES, 2013). Tal constituição indica a produção de práticas articulatórias agonísticas, as quais nenhuma fala autorizada poderia prever. É sob esse ângulo que podemos nos apropriar da noção de cenas de dissenso elaborada por Rancière para afirmar que, nos contextos organizacionais, o diálogo opera sob uma pretensa igualdade moral e política mobilizada por ações que visam a integração e colaboração - ainda que tais contextos sejam comumente marcados por tensões diversas e por uma pluralidade desigual e estilhaçada de vozes.

Nesse sentido, mais do que conceituar o diálogo nos cenários de uma organização - tarefa empreendida em trabalho anterior (MARQUES e MAFRA, 2013) esse artigo tem como objetivo compreender os mecanismos de operação do diálogo quando ele é mobilizado nos contextos organizacionais. Tais mecanismos serão entendidos a partir da convocação de algumas noções. Inicialmente, buscaremos 
entender que o diálogo emerge nos contextos organizacionais a partir de um acontecimento - algo que irrompe junto a um grupo e que atravessa o fluir das interações, provocando a abertura de campos dialógicos sempre conflituosos. Por isso, argumentamos que as interações provocadas pelo acontecimento dão origem a comunidades políticas ancoradas no dissenso, ou seja, em diferenças nos arranjos sensíveis que ordenam linguagens e gestos, e num desacordo sobre a situação posta sob o cotidiano organizacional.

Em seguida, será possível compreender que o diálogo mobilizado pelo acontecimento, ao promover a constituição de comunidades políticas, provoca também a criação de cenas de dissenso, por meio das quais os integrantes dessas comunidades instituem um drama, ancorado em gestos poéticos e argumentativos, voltados à sua própria constituição como interlocutores em torno de uma pretensa igualdade moral e política. Por fim, buscaremos entender como as comunidades políticas, que emergem das cenas de dissenso acontecimentais ao mesmo tempo em que as constróem, se valem do diálogo para dar visibilidade a (fazer aparecer) suas próprias diferenças, em práticas articulatórias imprevisíveis e conflituosas - configurando uma prosa social sempre aos cacos, múltipla em seus vários fragmentos.

\section{Acontecimento e comunidades políticas}

O acontecimento pode ser descrito, de modo geral, como um fato que irrompe e atravessa o vivido, trazendo rupturas e descontinuidades para a experiência. A apreensão do acontecimento como fato, nos permite localizá-lo no tempo e no espaço, atribuir-lhe uma individualidade e uma narratividade ao relacioná-lo a eventos passados, presentes e futuros. Ele seria, então, o ápice de uma trama causal. Mas a descrição do acontecimento como fato restringe seu entendimento a algo que possui um início e um fim, que pode ser observado e descrito, colocado em perspectiva e individualizado (QUÉRÉ, 2005).

Além disso, um acontecimento "pode ser palco de encontro, interação, confrontação e determinação recíproca" (QUÉRÉ, 2005, p.70). Sob esse viés, o 
acontecimento se configura como processo que põe em marcha uma transformação, uma ruptura e uma resistência à normalidade, instaura também um espaço comunicativo (reconfigurando-se e adquirindo outras dimensões e desdobramentos através das interações que acontecem nesse espaço) que reúne aqueles que o experimentam e o interpretam.

Forma-se, em torno e por causa de um acontecimento, uma comunidade, mas não no sentido de comunidade de comunhão, comunidade homogênea pela igualdade pressuposta entre seus membros e baseada em vínculos fortes, territoriais e exclusivos. A comunidade que se produz em torno de um acontecimento pode ser descrita como "política" (incluindo aí as dimensões estéticas, comunicacionais, sociativas e cívicas), uma vez que tem como principal característica o fato de ser fruto de um tipo de vínculo e de engajamento entre os sujeitos que as integram cuja finalidade é tentar, de forma argumentativa e dramática, articular negociações em torno da contextualização de momentos interlocutivos e performances que visam evidenciar a construção sensível, temporal e situacional do ato enunciativo (MARQUES, 2012).

O diálogo, ao operar sob a pressuposição de uma relação paritária (um querer falar e um querer escutar) define e desenha uma comunidade, mas tal comunidade "não possui consistência: ela é, a todo momento, carregada de um sujeito para outro, para uma infinidade virtual de vários outros. Ela possui um espaço, mas não funda um lugar" (RANCIÈRE, 2004, p.160). Assim, a comunidade não toma corpo como instituição social, uma vez que está suspensa, aguardando sempre a ação de sua constante verificação.

\footnotetext{
A comunidade dos seres falantes funda sua efetividade sobre uma violência cuja essência é tornar visível o invisível, dar um nome ao anônimo, fazer escutar uma palavra lá onde somente se percebia um ruído. (...) 0 procedimento de verificação da comunidade dentro da sociedade criaria um princípio de argumentação e um espaço polêmico, um espaço onde poderia se jogar a relação entre o semelhante e o dessemelhante, onde a frase igualitária apareceria como sujeita à verificação. Esse procedimento criaria uma comunidade (RANCIERE, 2004, p. 164 e 166).
}

Mas que tipo de acontecimento pode produzir uma comunidade política e também uma cena de dissenso? Para responder a essa questão, é necessário recortar 
melhor os conceitos de acontecimento e de comunidade. Neste trabalho, tomamos o acontecimento não só como "algo dotado da capacidade de transformar a percepção das coisas, de modificar a experiência e transformar a realidade" (QUÉRÉ, 2003, p.119), mas como algo que constrói e mobiliza os indivíduos como interlocutores. Dito de outro modo, o acontecimento que será aqui abordado é aquele que leva os sujeitos a se afirmarem como participantes de um mundo comum e de uma comunidade, que os convida a se perceberem como seres que não só usam a linguagem em situações dialógicas e contextos de enunciação, mas que também se constituem como sujeitos autônomos por meio dela. E, nesse sentido, um acontecimento pode instaurar comunidades nas quais os sujeitos de fala estabelecem vínculos em uma situação discursiva momentaneamente partilhada, sob a forma de um desejo reciprocamente expresso e que motiva a ação de "tomar a palavra", requerendo que se afirmem como "seres de razão e de discurso, capazes de contrapor razões e de construir suas ações como uma demonstração de capacidade que também é uma demonstração de comunidade" (RANCIÈRE, 2004, p.90).

A cena de dissenso é uma cena de aparição (QUÉRÉ, 1995), na qual atores, acontecimentos e problemas coletivos ganham visibilidade e adquirem seus contornos através de três tipos de ações intimamente ligadas ao "apparaître": as ações comunicativas, estéticas e políticas. Nem sempre é possível distingui-las com clareza, uma vez que as ações comunicativas (que dão origem ao e se configuram no espaço público) envolvem as negociações em torno da contextualização de uma situação interlocutiva, nas quais irrompem as intencionalidades que não são enunciadas, as vias do silêncio, o não dito, enfim, aspectos estéticos das interações simbólicas e das experiências dos sujeitos (a poiésis, a passibilidade, a criatividade, as táticas de questionamento e de resistência à opressão, a narrativa de si, etc.). Ao mesmo tempo, a instauração de uma situação de interlocução é também marcada por ações políticas que envolvem desde a avaliação de questões e a produção de justificativas e opiniões, até a capacidade que estas possuem de engendrar um mundo partilhado com os outros. 
Neste artigo, argumentamos que a dimensão interlocutiva e pragmática da linguagem é a situação agonística (MOUFFE, 2005), a cena polêmica da enunciação performática dos sujeitos que, ao lutarem para ter seus discursos considerados e para constituírem-se como interlocutores que desejam dizer e se fazer ouvir, estabelecem uma comunidade política que possui o mundo comum (amplamente partilhado) como pano de fundo preexistente para as interações e como fruto do processo de coexistência. Por isso, essa comunidade política é envolvida por uma disputa fundamental: ela é composta pela constante oposição entre mundos, entre indivíduos que fazem parte e aqueles que não se integram a um determinado comum, entre o justo e o injusto.

Em contextos organizacionais, comunidades políticas se formam, por exemplo, em torno de acontecimentos motivacionais promovidos por lideranças que, ao se servirem da ideologia da gestão, fingem reconhecer os trabalhadores valorizando-os por meio da elaboração estratégica de um discurso sobre suas competências e sua contribuição única para a instituição, sem assegurar-lhes as condições materiais e humanas de uma realização efetiva desses enunciados valorizantes sob a forma do verdadeiro reconhecimento de seus saberes e habilidades. Nesse caso, o reconhecimento manifesto publicamente por uma liderança se revela como puro traço retórico.

O fato de ser coberto de elogios em razão de certas qualidades ou competências parece ter-se tornado um instrumento de política simbólica, cuja função subjacente é integrar os indivíduos e grupos à ordem social dominante ao lhes oferecerem uma imagem positiva de si mesmos. Longe de contribuir para o aprimoramento da autonomia dos membros de nossa sociedade, o reconhecimento parece aparentemente servir à produção de representações adequadas ao sistema opressor (HONNETH, 2006, p.245).

Assim, no contexto organizacional, as práticas guiadas por um "falso" reconhecimento não promovem um aumento do poder e da autonomia dos sujeitos sociais, mas os conduzem ao assujeitamento. Lembramos que o processo de constituição de sujeitos autônomos se dá de maneira intersubjetiva e dialógica: envolve competências comunicativas que não existem como propriedades individuais, mas 
como parte de uma atividade compartilhada de busca comunicativa e dialógica por entendimento. Por isso, o indivíduo adquire autonomia somente através de seu envolvimento em uma rede de relações comunicativas com os outros (HABERMAS, 1987). A autonomia requer que consideremos nossos interlocutores como indivíduos que merecem igual consideração e que são moralmente capazes de elaborar, defender e revisar seus pontos de vista em público (COHEN, 1997). O igual tratamento exigido nessa relação tende a procurar formas de inclusão no diálogo que não sejam niveladoras de diferenças, permitindo que o "outro" seja respeitado em sua alteridade.

Quando uma liderança oferece um "falso" reconhecimento a seus colaboradores, ela corre o risco de que o sentimento de injustiça coletivamente percebido se transforme em centelha para a constituição de uma comunidade política que tenderá a expressar e nomear como dano a ausência de respeito ao trabalho por eles realizado e a barreira imposta à realização de sua autonomia.

É no cotidiano que a comunicação com o outro se fortalece, se redefine e redimensiona os sujeitos e o meio no qual se inserem. Contudo, devemos pensar que os sujeitos que se inserem nas práticas comunicativas do cotidiano desejam ter sua singularidade reconhecida, suas habilidades devidamente respeitadas e seu modo de viver incluído na "gramática" dos estilos de vida aprovados pela sociedade. Nesse sentido, os sujeitos elaboram demandas e reivindicações de reconhecimento social por meio das trocas discursivas e da linguagem. Por isso, nos realizamos através da linguagem e do uso que dela fazemos para nos vermos inseridos dentro de uma comunidade de sentidos, na qual negociamos pontos de vista para além de nossas diferenças (WARREN, 1995).

É importante salientar que uma comunidade política não tem como objetivo fazer coincidir semelhantes e desemelhantes, mas revelar que a partilha de um mundo comum é feita, ao mesmo tempo, da tentativa de estabelecer ligações entre universos fraturados e da constante resistência à permanência desses vínculos. Para Rancière, formas de agir e de ser do sujeito que tendem mais ao desentendimento e ao dissenso permitem instaurar uma comunidade política de partilha na qual a igualdade é o 
exercício constante de regular a proximidade e a distância entre seus membros. Seria preciso, então "aprender a recriar a cada instante o próximo e o distante que definem os intervalos da comunidade igualitária" (2004, p.199).

Uma comunidade política dissensual, de acordo com Rancière, interage menos para alcançar o entendimento e mais para tornar evidente um desacordo sobre a partilha de tempos, espaços e vozes entre os sujeitos. O vínculo e os modos de ação dos membros que integram uma comunidade dessa natureza privilegiam não uma reafirmação das diferenças entre grupos, mas uma reconfiguração da distribuição de ordens do visível, do audível e do comunicável, deslocando os limites e questionado uma ordem sensível excludente.

\begin{abstract}
A comunidade política é uma comunidade dissensual. O disensso não é em principio o conflito entre os interesses ou as aspirações de diferentes grupos. É, em sentido estrito, uma diferença no sensível, um desacordo sobre os próprios dados da situação, sobre os objetos e sujeitos incluídos na comunidade e sobre os modos de sua inclusão (RANCIÈRE, 2005, p.51).
\end{abstract}

A formação de uma comunidade política dissensual está associada ao modo como os sujeitos experimentam acontecimentos capazes de explicitar divisões e fronteiras, relações de poder e assimetria. Ao mesmo tempo, esses acontecimentos podem apresentar o potencial de reconfigurar uma partilha (divisão e compartilhamento) da realidade social baseada em formas discursivas de percepção que impõem limites à comunicabilidade da experiência daqueles que têm sua palavra excluída das formas autorizadas de discurso.

A comunicação sempre acontece permeada de relações de poder, desequilíbrio e agressividade e, por isso, estudos críticos de comunicação pretendem revelar e vencer formas assimétricas, explícitas e ocultas, de relações de poder que violam a reciprocidade (DEETZ e MCCLELLAN, 2009, p.445). Em diálogos que se estabelecem em contextos cívicos e organizacionais, a intenção persuasiva de comunicação é ocultada dos interlocutores, mantendo-se relações assimétricas de produção de sentido e de poder. Isso ocorre de várias maneiras, entre elas: "formações discursivas privilegiadas, comunicação sistemicamente distorcida (quando sistemas de poder dão a entender que 
a interação é livre e aberta) e comunicação discursivamente fechada (quando conflitos potenciais são suprimidos e tornados neutros)" (DEETZ, 2010, p.93). Todas as três revelam que diferenças de interesse são solucionadas por meio de "falsos diálogos", nos quais, sob a camuflagem de processos argumentativos e adversariais, decisões são tomadas entre posições conhecidas ao invés de incentivar a produção criativa do desconhecido e potencialmente mais vantajoso para a troca mútua.

A menção às relações de poder e às assimetrias comunicativas em situação de diálogo nos conduz a afirmar que não se pode tecer uma análise das trocas comunicativas e dialógicas em contextos organizacionais sem levar em consideração que grande parte delas é marcada pela hostilidade, pela desvalorização dos interlocutores e seus argumentos, pelas assimetrias de status entre os participantes e, sobretudo, pela não tematização de injustiças referentes ao próprio reconhecimento dos parceiros como moralmente dignos de serem vistos como interlocutores, como "pares". Sob esse aspecto, consideramos necessário examinar como as interações dialógicas dão a ver a criação de um espaço polêmico e dissensual no qual as diferenças podem aparecer e traçar caminhos de negociação e resistência.

\section{Cenas de dissenso: a poética das ações políticas}

A caracterização da cena de dissenso (ou cena polêmica) é central no pensamento político de Rancière, uma vez que, para ele, o real objeto do conflito político é justamente a existência de uma situação de fala e o status de validade dos participantes nessa situação. Cenas de dissenso se constituem, segundo Rancière, quando ações de sujeitos que não eram, até então, contados como interlocutores, irrompem e "provocam rupturas na unidade daquilo que é dado e na evidência do visível para desenhar uma nova topografia do possível" (2008, p.55). São essas cenas polêmicas que permitiram a redisposição de objetos e de imagens que formam o mundo comum já dado, ou a criação de situações aptas a modificar nosso olhar e nossas atitudes com relação ao ambiente coletivo, questionando uma ordem dominante que apaga conflitos, diferenças e resistências. 
Em tais cenas, os sujeitos podem experimentar a política como experiência e acontecimento, uma vez que ela deriva do processo de criação de formas dissensuais de expressão e comunicação que inventam modos de ser, ver e dizer, configurando novos sujeitos e novas formas de enunciação coletiva (RANCIÈRE, 2004). Na cena de dissenso se busca retirar os corpos de seus lugares assinalados, libertando-os de qualquer redução à sua funcionalidade. Para Rancière, essa cena mistura a dramaticidade da cena teatral com a racionalidade da cena argumentativa: "não se pode separar uma ordem racional de argumentação de uma ordem poética do comentário e da metáfora, pois a política é produzida por atos de linguagem que são, ao mesmo tempo, argumentações racionais e metáforas poéticas" (RANCIÈRE, 1995, p. 86). Por isso, a experiência política dissensual é também permeada pela estética: o sujeito autônomo é um ser que toma a palavra encenando-a diante do outro, e é também um sujeito poético que reconfigura materialmente e simbolicamente o território do comum.

\footnotetext{
Para entrar em uma troca política, torna-se necessário inventar a cena na qual as palavras ditas se tornam audíveis, na qual os objetos podem se fazer visíveis e os indivíduos podem ser reconhecidos. É nesse sentido que podemos falar de uma "poética da política" (RANCIÈRE, 2000, p.116).
}

A poética da política, ou a existência de uma base estética para a política, além de ser um desafio à oposição entre interlocutores legítimos e ilegítimos, remete à invenção da cena de interlocução na qual se inscreve a palavra do sujeito falante, e na qual esse próprio sujeito se constitui de maneira performática (MARQUES e MAFRA, 2013). A construção do interlocutor organizacional pelo caminho da estética e das performances de resistência pode, por exemplo, ser potencializada pela discussão sobre as cenas de dissenso; a partilha política do sensível, e a construção de um sujeito político que se produz na medida em que cria uma cena de dissenso, assumindo, publicamente, um lugar dramático/irônico/cômico/argumentativo junto aos seus parceiros organizacionais. Neste caso, performances de resistência envolvem uma intervenção ativa e subversiva sobre práticas e discursos sociais e institucionais. 
Como salientam Spicer et al. (2009), nos estudos críticos sobre a comunicação no contexto das organizações olha-se para a performatividade como os modos práticos e críticos de aproriação e uso dos discursos, revelando as condições de opressão e revelando os desencaixes e fraturas entre os sujeitos e seus mundos, os quais não podem ser superados de maneira definitiva, mas deixam entrever momentos fugazes de uma aproximação sempre tensa.

A ação política, assim como a comunidade política, são dialógico-dissensuais para Rancière e dizem respeito à proposição de contextos, de situações comunicativas nas quais as posições de sujeito são testadas, negociadas e revistas em uma cena que é fruto da combinação entre argumentos e encenação dramática, da conexão e desconexão entre os múltiplos nomes que definem os sujeitos. Essa combinação deriva do fato de que, segundo Rancière (1995), a argumentação política é, ao mesmo tempo, a construção racional de pontos de vista e a demonstração de um mundo possível no qual tais pontos de vista podem contar como argumentos. Por isso, a argumentação política é, ao mesmo tempo, a demonstração de um mundo possível no qual o argumento pode contar como argumento. Tal demonstração é acontecimental, estética, performática e dramática: ela é uma atividade de invenção que permite uma redescrição e reconfiguração do mundo comum da experiência (MARQUES, 2013).

Sob a perspectiva de Rancière (2004), a constituição do ator social como interlocutor deve considerar as seguintes dinâmicas: a) cada ator deve ver-se como sujeito de palavra e não só de voz; b) cada ator deve construir sua autonomia política, isto é, suas habilidades de elaborar argumentos e torná-los inteligíveis através da explicitação do mundo no qual eles eles fazem sentido e, com isso, despertam empatia; c) cada ator deve desidentificar-se com nomes que lhes foram atribuídos de maneira hierárquica, ou seja, deve buscar existir na conexão e desconexão de vários nomes.

É considerando essa perspectiva que salientamos a importância assumida por acontecimentos que produzem cenas de dissenso e comunidades políticas nas quais os sujeitos "aparecem", desenvolvem argumentativamente um problema que os afeta, dialogam e revelam os contextos nos quais seus argumentos e demandas fazem sentido. 


Elementos para a criação de
cenas de dissenso
Os sujeitos e seu aparecer na
cena

Invenção e criação de uma cena

Interação

Argumento e contexto

Fonte: elaboração dos autores.
O que observar na prática dialógica em contextos organizacionais

Investigar modos de visibilidade, apresentação do mundo do sujeito e de sua experiência vivida. São relevantes os corpos, os gestos, as performances e as narrativas.

Como se dá a constituição do interlocutor: perceber a si mesmo como sujeito de palavra, de discurso e as implicações disso na construção do diálogo.

a) Observar o desdobramento argumentativo de um problema; b) atentar para a dramatização que inscreve sobre o espaço comum aqueles que contam; c) avaliar a relação conflitual entre os nomes que definem o sujeito.

Colocar em questão a possibilidade de diálogo e a igualdade dos participantes.

Revelar o mundo no qual os argumentos de um sujeito contam como tais. $\mathrm{O}$ argumento não pode ser separado da singularidade do sujeito e de seu universo particular.

Os elementos para a criação de cenas de dissenso, presentes nas múltiplas e nunca totalmente previsíveis práticas dialógicas que irrompem nos contextos organizacionais, permitem a identificação do diálogo não como espaço voltado a harmonizar as diversas cenas interlocutivas possíveis, mas como âmbito efetivo de trocas, por meio do qual os sujeitos organizacionais se valem do conflito e da articulação dramática/argumentativa para serem vistos, em suas diferenças, como interlocutores moralmente considerados a tomar parte num debate. Tal movimento, notadamente impulsionado pelas comunidades políticas, imputa, à cena organizacional, a expressão de uma pluralidade de vozes que se valem do diálogo para dar visibilidade a (fazer aparecer) suas próprias diferenças, instaurando o quadro de uma prosa social sempre fragmentada/estilhaçada.

\section{Pluralidade e aparência: uma experiência dialógica estilhaçada}

Ainda que, por vezes, sejam opacas à fala autorizada da organização, as comunidades políticas que emergem do acontecimento e das cenas de dissenso instituem uma prosa social aos pedaços, um diálogo aos cacos (MAFRA, 2011). Tal 
diálogo, ao contrário de uma atividade harmônica pautada por um suposto uníssono, é tributário de uma comunicabilidade fragmentada, em práticas articulatórias múltiplas, imprevisíveis e agonísticas, por meio das quais engendra-se, em âmbitos interacionais possíveis, uma aparição às diferenças dos sujeitos aspirantes à igualdade moral e política.

Sendo assim, o diálogo se vale de um estranhamento mútuo, por meio do qual posições de sujeito inusitadas podem emergir na cena interlocutiva. Deleuze (2007) nos ajuda a compreender a natureza de tais processos comunicativos, quando dirige um olhar ao próprio acontecimento: "as singularidades se distribuem em um campo propriamente problemático e advém neste campo como acontecimentos topológicos aos quais não está ligada nenhuma direção (singularidades livres, anônimas e nômades)" (DELEUZE, 2007, p.107).

Pelos termos desse autor, podemos entender as singularidades como as próprias efetuações do acontecimento: elas não se ligam a direção alguma e se produzem em uma multiplicidade de posições livres, anônimas e nômades, que emergem em função do corte acontecimental junto aos também mutantes e múltiplos processos dialógicos. Tais processos não se realizam na medida em que são contínuos e consensuais; mas, ao contrário, o diálogo parece emergir numa imprevisibilidade e numa descontinuidade, em si mesma, ininterrupta.

Esse diálogo fraturado, aos cacos, insinua a imagem de uma interação organizacional que não pode ser direcionada, organizada e estrategicamente orientada, ponto-a-ponto. É por isso que o acontecimento chacoalha as estruturas estratégicas: como compreender algo instável e flutuante? Como mensurar uma interação que é sempre difusa e caótica? Por mais que advoguem pelo controle do acontecimento, as estratégias de comunicação organizacionais se perdem em meio a esse fluxo: oferecem enquadramentos, mas não molduras precisas da realidade; se valem de performances como as dos sujeitos - e se vestem de descrições aparentemente fixas; buscam condensar formas de experiência que são igualmente fraturadas pelo dissenso e pelo acontecimento (MAFRA, 2011), ainda que, deles, tentem se esquivar. 
Nesse contexto, um público não é uma entidade fixa, mas é instância móvel, que passa por um processo mesmo de experenciação - não apartado das inusitadas posições de sujeito que podem insurgir atravessadas pela presença dos outros, junto à efetuação de dimensões acontecimentais. Além disso, não podemos nos esquecer de que esses inúmeros outros se estranham, em agonia recíproca; ora se aglutinam, ora se repulsam, em articulações discursivas que constituem os campos de comunicabilidade em meio aos quais eles emergem. Sendo assim, tendo em vista a natureza instável e diversificada do diálogo nos contextos organizacionais, dois aspectos se mostram particularmente caros à empreitada de problematização dessa prosa aos pedaços provocada pelo diálogo nos contextos organizacionais: 1) a pluralidade; e 2) a aparência.

A pluralidade parece ser um movimento político constitutivo que se impõe junto às cenas de dissenso acontecimentais e às comunidades que insurgem nos cenários organizacionais. Para Hannah Arendt (1999; 2007; 2008) "a política se baseia no fato da pluralidade humana; (...) diz respeito à coexistência e associação de homens diferentes". Por conta disso, Arendt (1999) toma a política como fenômeno (e não como objeto) e entende que sua existência, antes de tudo, só é possível pela relação entre homens diversos, múltiplos, distintos. Em tal relação, a própria política se revela, portanto, como âmbito da vida que acolhe a pluralidade como condição de humanidade e como possibilidade da vida coletiva, de modo que os homens não poderiam coexistir como homens-em-conjunto se não puderem se valer de suas próprias diferenças.

De tal sorte, Arendt (2007) entende o espaço público como o âmbito essencial da política, a esfera em que se torna possível a criação de um mundo comum pela livre expressão das diferenças entre os homens, o espaço em que a realidade humana é produzida com a presença do outro. De tal forma, é somente quando expressam publicamente suas diferenças que os homens podem compreender o mundo em que vivem, com vistas a modificá-lo permanentemente. É assim que, tendo os sujeitos a primazia da liberdade e da ação diante dos outros, Arendt (1999) enxerga o espaço público como o âmbito da vida que, por princípio, acolhe indivíduos em igualdade moral e política - ou seja, com possibilidades iguais de participação em uma comunidade 
política que busca garantir o permanente movimento de reconhecimento e de legitimação de suas diferenças constitutivas, em meio à construção de um mundo comum.

Para Arendt (2008), a partir do momento em que as diferenças entre os homens não podem mais ser expressas, o mundo comum passa a ser o mundo de alguns: os homens passam a viver subjugados; perdem sua condição de humanidade e existem como objetos na mão de outros homens que os tratam como coisas.

As cenas de dissenso, em última análise, buscam trazer, aos contextos organizaconais, as condições para a existência de uma espécie de humanidade (ou humanização, nos termos de Mumby (2010)) - ainda que as mesmas coexistam com as demandas por instrumentalização do próprio trabalho e/ou da natureza das atividades organizacionais. Tais condições são politicamente constituídas pela aparência de sujeitos que correm riscos: enquanto a diferença é individualizada/particularizada, ela não ganha existência nem para o outro nem para a comunidade dos homens - isto é, não ganha existência pública, muito menos política. Dessa forma,

\footnotetext{
a aparência - aquilo que é visto e ouvido pelos outros e por nós mesmos constitui a realidade. Em comparação com a realidade que decorre do fato de que algo é visto e escutado, até mesmo as maiores forças da vida íntima (...) vivem uma espécie de vida incerta e obscura, a não ser que, e até que, sejam transformadas, desprivatizadas e desindividualizadas, por assim dizer, de modo a tornar-se adequadas à aparição pública. (...) Ser visto e ouvido por outros é importante pelo fato de que todos veem e ouvem de ângulos diferentes. (ARENDT, 2007, p. 59-67).
}

A desprivatização e a desindividualização que Arendt (2007) tanto advoga são gestos dialógicos que se constituem pelo dissenso. Nas palavras de Arendt (1974, p.34), "o mundo não é humano por ter sido feito pelos homens e tampouco se torna humano porque a voz humana nele ressoa, mas somente quando se torna objeto de diálogo". No entanto, não se pode também desconsiderar que, com a pluralidade, se achega o estranhamento: a emergência da diferença também insinua um processo de disputas e de lutas por ocupação de visões e de articulações acerca das cenas de dissenso instituídas, particularmente em contextos organizacionais marcados pelas assimetrias de poder, nem sempre superadas. Nesse sentido, no contexto organizacional o diálogo 
acontece aos cacos, num fluxo fragmentado, múltiplo, imprevisível, ora opaco, ora visível, sempre orientado pelas pretensões de igualdade moral e política e pelo movimento de sujeitos que correm riscos para instituírem o novo pela cena dissensual.

\section{Considerações finais}

Acreditamos que a reflexão acerca da constituição de comunidades políticas pela via do acontecimento, juntamente com a noção de cena de dissenso proposta por Rancière (na qual sujeitos "aparecem" em sua pluralidade e dramaticidade) nos ajudam a iluminar melhor um dos cernes do processo dialógico: a constituição do sujeito político autônomo, digno de reconhecimento e que se auto-reconhece situacionalmente como par, como parceiro, como interlocutor que se configura em uma cena polêmica, e ao mesmo tempo em que a cria e renova.

Nesse sentido, os modos como o diálogo opera nos contextos organizacionais presentes podem ser melhor apreendidos por uma reflexão que contemple e articule: i) a negociação de um pano de fundo compartilhado (senso comum, espaço público) e diante do qual se definem posicionamentos que caracterizam cenas dissensuais que combinam estética e política; ii) a estrutura argumentativa e "teatral" (cênica) das trocas dialógicas; iii) as interseções entre diferentes formas de comunicação utilizadas e permitidas pela diversidade de uso das linguagens (agressividade, humor, retórica, sinais visuais de assentimento ou repreensão, testemunho, uso de imagens, etc.), de modo a construir diálogos que permitam a expressão das diferenças e a reflexão sobre aspectos da identidade e da alteridade.

Ressaltamos a importância de privilegiarmos os sujeitos e seu "aparecer" na cena de dissenso, sua percepção como sujeitos de palavra e de discurso, sua relação em uma comunidade política e o modo como inventam e criam cenas nas quais há uma interseção entre o conteúdo do argumento proferido e a pluralidade dos sujeitos e de seus contextos de vida e ação. 


\section{Referências}

ARENDT, Hannah. A condição humana. 10ạ ed. Rio de Janeiro: Forense Universitária, 2007.

ARENDT, Hannah. A promessa da política. Rio de Janeiro: DIFEL, 2008.

ARENDT, Hannah. O que é política? 2a ed. Rio de Janeiro: Bertrand Brasil, 1999.

ARENDT, Hannah. Los orígenes del totalitarismo. Madrid, Taurus, 1974

COHEN, Joshua (1997). "Procedure and Substance in Deliberative Democracy". In: BOHMAN, James; REHG, William (eds.). Deliberative Democracy: essays on reason and politics. Cambridge: MIT Press, p.407-437.

DEETZ, Stanley. Comunicação Organizacional: fundamentos e desafios. In: MARCHIORI, M. (org.). Comunicação e Organização: reflexões, processos e práticas. São Caetano do Sul: Difusão, 2010, pp.83101.

DEETZ, Stanley.; McCLELLAN, John. Communication and critical management Studies. In H. Willmott, T. Bridgman and M. Alvesson (eds.), Handbook of critical management studies, 2009, pp. 433-453.

DEETZ, Stanley; SIMPSON, Jennifer. Critical Organizational Dialogue: Open Formation and the Demand of "Otherness". In: R. Anderson, L. Baxter, and K. Cissna (eds), Dialogic Approaches to Communication. Thousand Oaks, CA: Sage, 2003.

DELEUZE, Gilles. Lógica do Sentido. São Paulo: Perspectiva, 2007.

FAIRHURST, G.; PUTNAM, L. Organization as discursive constructions. Communication Theory, v.14, n.1, 2004, p.5-26.

HABERMAS, Jürgen (1987). The Theory of communicative action: vol.Il Lifeworld and system: a critique of functionalism reason. Boston: Beacon Press.

HONNETH, Axel. "La reconnaissance comme idéologie ». In : La société du mépris : vers une nouvelle théorie critique. Paris : La Découverte, 2006, pp.245-274.

MAFRA, Rennan. Vestígios da dengue no anúncio e no jornal: dimensões acontecimentais e formas de experiência pública na (da) cidade. Tese de Doutorado. Programa de Pós-Graduação em Comunicação. Belo Horizonte: Universidade Federal de Minas Gerais, 2011.

MARQUES, Angela; MAFRA, Rennan. Diálogo no contexto organizacional e lugares de estratégia, argumentação e resistência. Organicom, № 18, 2013 (no prelo).

MARQUES, A. Três bases estéticas e comunicacionais da política: cenas de dissenso, criação do comum e modos de resistência. Contracampo. , v.26, p.126 - 145, 2013.

MARQUES, A. C. S. Acontecimento e criação de comunidades de partilha: o papel das ações comunicativas, estéticas e políticas. In: FRANÇA, Vera Veiga; OLIVEIRA, Luciana de (Orgs.). Acontecimento: reverberações. Belo Horizonte: Autêntica Editora, 2012, v. , p. 143-156.

MOUFFE, C. (2005) For an agonistic model of democracy. In: The democratic paradox. Londres: Verso, pp.80-107.

Dispositiva - v.2, n.2 (2014): novembro, 2013 - junho, 2014 
MUMBY, Dennis. Reflexões críticas sobre comunicação nas organizações. In: Kunsch (org). A comunicação como fator de humanização das organizações. São Paulo: Difusão, 2010, p.19-39.

PUTNAM, Linda; NICOTERA, Anne. Communicative constitution of organization is a question: critical issues for addressing it. Management Communication Quarterly, v.24, n.1, 2010, p.158-165.

QUÉRÉ, L. Entre facto e sentido: a dualidade do acontecimento. Trajectos. Revista de Comunicação, Cultura e Educação, Lisboa, n. 6, p. 59-75, 2005.

QUÉRÉ, Louis. "Le public comme forme et comme modalité d'expérience", CURAPP, Le sens du public, Paris: PUF, 2003, p.113-133.

QUÉRÉ, Louis. « L'espace public comme forme et comme événement », dans JOSEPH, Isaac (dir.). Prendre Place : espace public et culture dramatique. Pontigny-Cerisy : Éditions Recherches, 1995, pp.93-110.

RANCIÈRE, Jacques. La Mésentente- politique et philosophie. Paris: Galilée, 1995.

RANCIÈRE, Jacques. Le Partage du Sensible: esthétique et politique. Paris: La Fabrique éditions, 2000.

RANCIÈRE, Jacques. Sobre políticas e estéticas. Museu d'Art Contemporania de Barcelona, 2005.

RANCIÈRE, J. (2004). Aux bords du politique. Paris, Gallimard, 262p.

RANCIÈRE, Jacques. As Desventuras do Pensamento Crítico. In: Crítica do contemporâneo: Giorgio Agamben, Giacomo Marramao, Jacques Ranciere, Peter Sloterdijk. São Paulo: Fundação Serralves, 2008, p.79-102.

SPICER, André; ALVESSON, Mats; KÄRREMAN, Dan. Critical performativity: The unfinished business of critical management studies, Human Relations, v. 62, n.4, 2009, p.537-560.

WARREN, Mark (1995). The self in discursive democracy. In: WHITE, Stephen (ed.). The Cambridge Companion to Habermas. Cambridge University Press, p.167-200. 